\title{
Enhanced strength, stiffness and elongation potential of paper by spray addition of polysaccharides
}

\author{
Anders Strand (1) - Jarmo Kouko • Antti Oksanen • Kristian Salminen • \\ Annika Ketola $\cdot$ Elias Retulainen $\cdot$ Anna Sundberg
}

Received: 5 July 2018/ Accepted: 1 February 2019/Published online: 8 February 2019

(C) The Author(s) 2019

\begin{abstract}
The effects of spray additions of alginate, cationic guar gum, or chitosan on paper properties were determined. The aim of this study was to enhance the mechanical properties of papers after unrestrained drying, while maintaining or increasing the extraordinarily high elongation potential of these papers. The mechanical characteristics of the different polysaccharides were determined by tensile test of model films. Alginate resulted in very strong and stiff films with low strain at break values, while cationic guar gum and chitosan resulted in significantly weaker and
\end{abstract}

A. Strand $(\bowtie) \cdot$ A. Sundberg

The Laboratory of Wood and Paper Chemistry, Åbo Akademi University, Porthaninkatu 3, FI-20500 Turku, Finland

e-mail: anders.strand@abo.fi

A. Sundberg

e-mail: anna.sundberg@abo.fi

J. Kouko · A. Oksanen · K. Salminen ·

A. Ketola $\cdot$ E. Retulainen

VTT, Koivurannantie 1, FI-40400 Jyväskylä, Finland

e-mail: jarmo.kouko@vtt.fi

A. Oksanen

e-mail: antti.oksanen@vtt.fi

K. Salminen

e-mail: kristian.salminen@vtt.fi

A. Ketola

e-mail: annika.ketola@vtt.fi

E. Retulainen

e-mail: elias.retulainen@vtt.fi softer films with high strain at break. The polysaccharide solutions were sprayed onto wet handsheets, and the paper properties were measured after restrained and unrestrained drying. The spray additions increased the tensile index, density, and tensile stiffness of the handsheets. Spray addition of alginate resulted in stiffer and stronger paper than the other tested polysaccharides. Alginate was able to increase the tensile index of the paper by $54 \%$ and the tensile stiffness by $32 \%$ after restrained drying. All strain at break values in this study correlated linearly with paper shrinkage during drying. Alginate, which gave extremely strong and stiff model films, enhanced paper shrinkage, effectively lowered the air permeability of the paper, and formed a polysaccharide film on top of the paper, was found to be the most promising candidate for future packaging applications. 


\section{Graphical abstract}

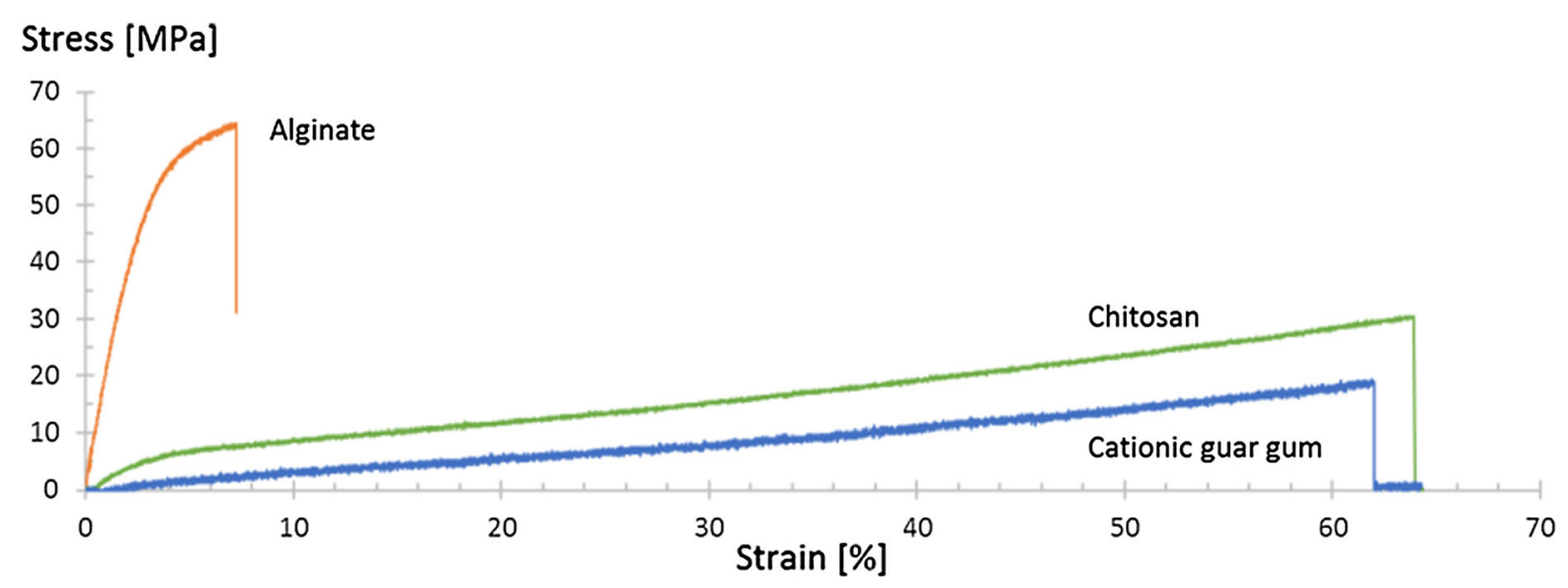

Keywords Paper properties - Alginate - Guar gum · Chitosan · Spraying · Extendable fiber network · Unrestrained drying $\cdot$ Paper shrinkage

\section{Introduction}

Novel bio-based alternatives to fossil-based plastics are needed for future packaging applications. So far, the bio-based alternatives have been limited by their brittleness, low thermal stability, medium gas barrier properties, and low solvent resistance (e.g. against water) (Yu et al. 2006; Rhim 2012). Cellulose is an optimal choice of raw material for such applications, since it is biodegradable, renewable, recyclable, and currently available in large quantities. It has been reported that highly extensible cellulose-based fiber networks can be created, and can be molded into 3D shapes using available forming techniques (Svensson et al. 2013; Vishtal et al. 2014; Vishtal and Retulainen 2014b). Mechanical treatments of fibers and additions of various additives have been used in combination with unrestrained drying to improve the extensibility of fiber networks (Seth 2005; Zeng et al. 2013; Khakalo et al. 2014, 2017a; Vishtal et al. 2015; Strand et al. 2017). Paper shrinkage during unrestrained drying has been shown to cause micro-compressions in the longitudinal direction of the fibers (Page and Tydeman 1962). It is known that unrestrained drying affects the mechanical properties of paper quite severely. Unrestrained drying of paper increases its strain at break significantly at the cost of tensile index and tensile stiffness (see e.g. Zeng et al. 2013; Strand et al. 2017). Stretching a shrunken fiber network is to a certain extent a reversal of shrinkage, as the applied forces tend to pull out the kinks and micro-compressions, both between and within the bonds. As intrafiber hydrogen bonds gradually break, the micro-compressions are released, allowing for a greater extension of the fiber network before it breaks due to actual failure of fiber-fiber bonds and resulting localization of stresses. For a pulp with constant refining level, a linear correlation between strain at break and negative strain, i.e. shrinkage, has previously been reported for paper, both in machine direction and cross direction (Wahlström 1999). However, recent results indicate that the relationship between shrinkage and elongation is non-linear in large scale and that the same dimensional contraction brought about by shrinkage can be strained out in tensile testing (Kouko and Retulainen 2018). It was shown that the strain at break of paper after unrestrained drying increases linearly with increasing refining energy and that it influences most mechanical properties of the paper considerably (Strand et al. 2018).

Addition of hydrophilic polysaccharides or polyelectrolytes is known to enhance the bonding between fibers and is the most common strategy to increase paper strength (Hubbe 2006; Hubbe et al. 2009; Fornue et al. 2011). For successful wet-end additions, the additives need to be retained to the fibers and have sufficiently high molar mass to avoid migration into the fiber pores (Pelton 2004; Hubbe 2006; Fornue et al. 
2011). It is also beneficial if the additives are hydrophilic and able to form hydrogen bonds. Dry strength agents are generally water-soluble polymers, meaning that the effectiveness of the additives is largely governed by the retention of the additive to the fiber network. Recent studies have been able to circumvent the reliance on retention to some extent by performing spray additions of various additives onto already formed, wet paper sheets (Lindqvist et al. 2014; Khakalo et al. 2014; Vishtal and Retulainen 2014a; Vishtal et al. 2015). This methodology has previously been used with agar, gelatin, and combinations of gelatin and agar to enhance paper properties. Spray additions of agar and gelatin in combination with unrestrained drying have been shown to result in high strain at break of paper. In the current study, some additional polysaccharides were selected for spray addition.

Alginates are anionic unbranched block co-polymers of $\beta$-D-mannosyluronic acids and $\alpha$-L-gulosyluronic acids linked $1-4$. The blocks can be either homopolymers of either mannosyluronic or gulosyluronic units or a heteropolymer of both units (Fig. 1; Gacesa 1988; BeMiller and Whistler 1996). The conformation of these units are different; blocks of mannosyluronic acids will therefore form a ribbonlike structure while blocks of gulosyluronic units will form a buckled chain. Alginate readily forms hydrogels and are used as stabilizers, gelling agents, thickening agents or as films or fibers.

Guar gum is extracted from the pods of the guar plant (Cyamopsis tetragonoloba) (Chudzikowski 1971; BeMiller and Whistler 1996; Mudgil et al. 2014). This polysaccharide have a linear backbone of 1-4-linked $\beta$-D-mannosyranose units with 1-6-linked $\alpha$-D-galactopyranos as side groups. The ratio of mannose to galactose is about 1.6-1.8:1 (Fig. 1; BeMiller and Whistler 1996; Mudgil et al. 2014). Guar gum is water soluble and has a very high molar mass. Guar gum is used as additives in e.g. food, pharmaceuticals, paper, textile, explosives, oil well drilling and cosmetics industry (Mudgil et al. 2014). Guar gums can easily be modified and cationic guar gum (guar hydroxypropyltrimonium chloride) is used in e.g. cosmetics as an emulsifier.

Chitin is, after cellulose, the second most produced polysaccharide annually in the world. Chitin is found in the support material of crustaceans, as shrimp and crabs, and insects. It is a polysaccharide that is composed of 1-4-linked $\beta$-N-acetyl-D-glucosamine (Fig. 1; Rinaudo 2006). Chitin is not water soluble but its N-deacetylated derivate, chitosan, is soluble in water at slight acidic conditions. Chitosan is the only pseudonatural cationic polysaccharide, with a $\mathrm{pK}_{\mathrm{a}}$ of about 6.3-6.7, and it also contains a high percentage of nitrogen (Ravi Kumar 2000; Rinaudo 2006). Chitosan is biocompatible, biodegradable and non-toxic and it is used in many application such as food, cosmetics, textiles, pharmaceuticals and nanomaterial (Ravi Kumar 2000; Rinaudo 2006; Shukla et al. 2013).

The aim of this study was to enhance the tensile strength, tensile stiffness and strain at break of handsheets after restrained and unrestrained drying by spray application of different available polysaccharides onto wet handsheets. Model films from the polysaccharides were also prepared and tested in order to gain information about their mechanical properties.

\section{Materials and methods}

\section{Materials}

ECF-bleached, once-dried softwood kraft pulp was obtained from a Finnish pulp mill. Alginic acid sodium salt from brown algae (alginate) was obtained from Sigma-Aldrich. According to the supplier, the alginate consisted of approximately $61 \%$ mannosyluronic units, and $39 \%$ gulosyluronic units, with 19-25\% carboxyl groups, and an approximate $M_{w}$ of $240 \mathrm{kDa}$. The alginate powder was directly dissolved in distilled water to a concentration of $1 \mathrm{wt} \%$ with the aid of boiling and agitation. Chitosan (medium molecular weight) was obtained from Sigma-Aldrich. According to the supplier, the $\mathrm{M}_{\mathrm{w}}$ of the chitosan was $190-310 \mathrm{kDa}$, and the degree of deacetylation was $75-85 \%$. The cationic charge density of the chitosan was $4.7 \mathrm{meq} / \mathrm{g}$, determined by polyelectrolyte titration using a particle charge analyzer (Mütek PCD 03, Mütek Analytic GmbH, Germany; BTG, Switzerland). The chitosan powder was dissolved in $1-1.5 \%$ acetic acid to a concentration of $1 \mathrm{wt} \%$ with the aid of boiling and agitation. Cationic guar gum (guar hydroxypropyltrimonium chloride) was obtained from Making Cosmetics, USA. The reported viscosity of a $1 \%$ solution $\left(20 \mathrm{rpm}, 20^{\circ} \mathrm{C}\right)$ was $3000-4000 \mathrm{cP}$, according to the supplier. The charge density of the cationic guar gum was $0.8 \mathrm{meq} / \mathrm{g}$, determined by 

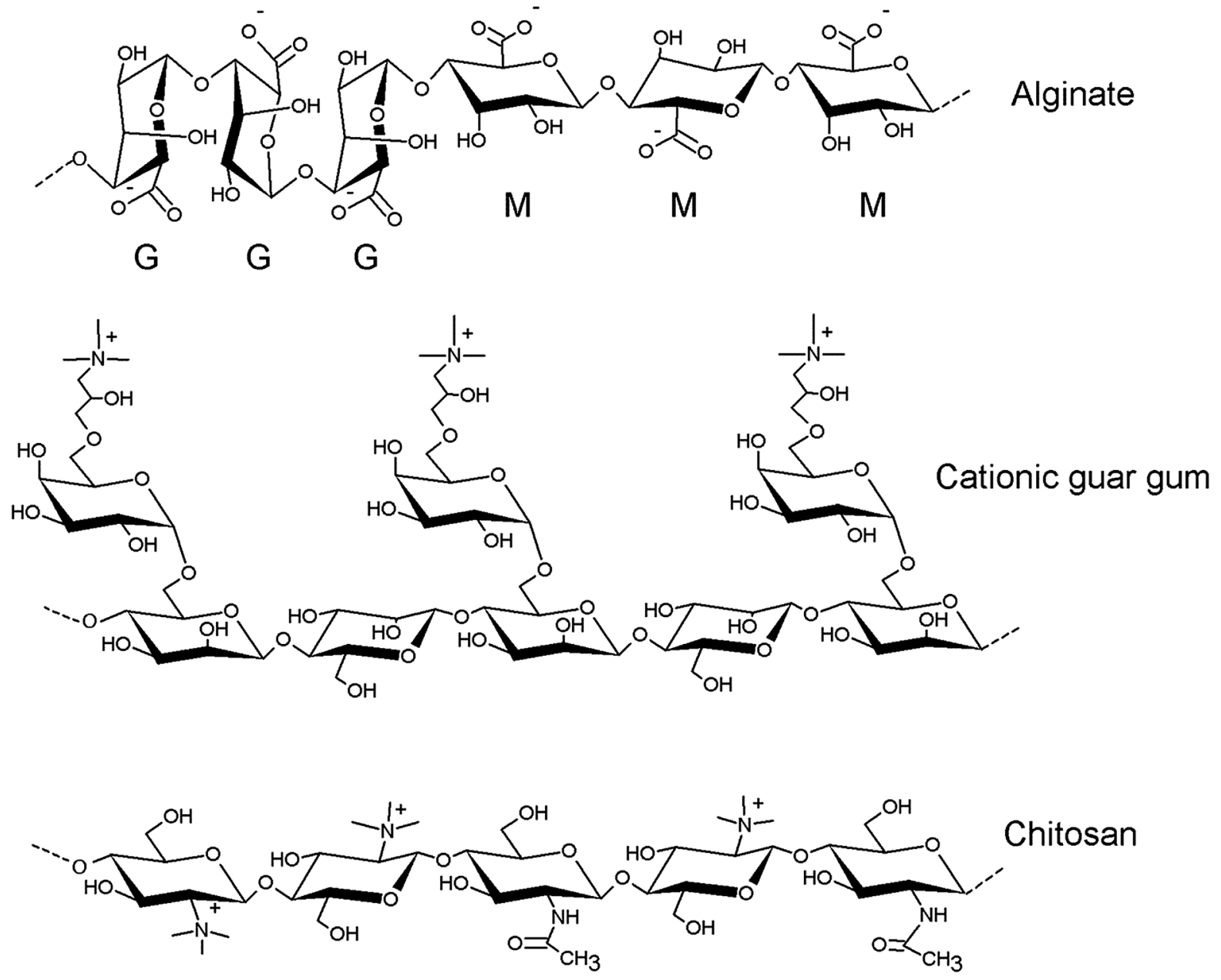

Fig. 1 The chemical structures of alginate, cationic guar gum, and chitosan. $G$ gulosyluronic units, $M$ mannosyluronic units

polyelectrolyte titration using a particle charge analyzer. The cationic guar gum powder was dissolved in distilled water to a concentration of $0.5 \mathrm{wt} \%$ with the aid of boiling and agitation. Sorbitol was obtained from Sigma-Aldrich and directly dissolved in distilled water to a concentration of $20 \mathrm{wt} \%$. Sorbitol was required as a softener during film casting.

\section{Methods}

\section{Preparation of model films from polysaccharides}

The solvent casting of the polysaccharide model films were performed similarly to a previously reported method (Rhim 2012). The polysaccharide solution was mixed with sorbitol solution and the mixture was then poured into Teflon-coated petri dishes (diameter
$85 \mathrm{~mm}$ ). The water evaporated from the molds at room temperature during the course of a few days, resulting in model films of the different polysaccharides. The films were then carefully removed from the petri dishes.

\section{Testing of model polysaccharide films}

The thickness of the model films were measured using a Lorentzen \& Wettre thickness tester with an accuracy of $0.1 \mu \mathrm{m}$. Small "dog bone" shaped test pieces were cut from the polysaccharide model films. The linear area of the test piece was $4 \mathrm{~mm}$ in width and $30 \mathrm{~mm}$ in length. The tensile tests were performed with an Instron 8872 apparatus, controlled by Bluehill3 software. The chosen straining speed was $2 \mathrm{~mm} /$ $\min$. The tensile tests were performed at least three 
times. The obtained raw data was recalculated from load $(\mathrm{N})$ into stress $(\mathrm{MPa})$ and from extension $(\mathrm{mm})$ into strain (dimensionless), in order to determine the elastic modulus of the tested samples.

\section{Polysaccharide viscosity measurements}

Solutions of the different polysaccharides were prepared with their previously described solvents; $1 \mathrm{wt} \%$ of alginate and chitosan, and $0.5 \%$ of cationic guar gum. The viscosities of the polysaccharide solutions were determined using a Paar Physica MCR (modular compact reometer) apparatus (rod: CC27, cup: TEZ $150 \mathrm{P})$. The shear rate gradually increased from 0.01 to $1000 \mathrm{~s}^{-1}$ (Fig. 2). The measured viscosity at a shear rate of $1.1 \mathrm{~s}^{-1}$ was $259 \mathrm{mPas}$ for the $1 \%$ alginate solution, $251 \mathrm{mPas}$ for the $1 \%$ chitosan solution, and $668 \mathrm{mPas}$ for the $0.5 \%$ cationic guar gum solution.

\section{Refining of pulp}

The low-consistency refining of the kraft pulp was performed with a ProLab ${ }^{\mathrm{TM}}$ refining station (Valmet, Finland) at Åbo Akademi University (Turku, Finland) according to a previously described procedure (Strand et al. 2017). The Schopper-Riegler ( ${ }^{\circ} \mathrm{SR}$ ) values of the refined pulp was measured according to ISO 5267-1, and parallel samples of the refined pulp was characterized using a Kajaani Fiberlab optical fiber analyzer (Metso Automation, Finland) (Table 1). The pulp was refined to $135 \mathrm{kWh} / \mathrm{t}$, which corresponded to ${ }^{\circ} \mathrm{SR} 25$.

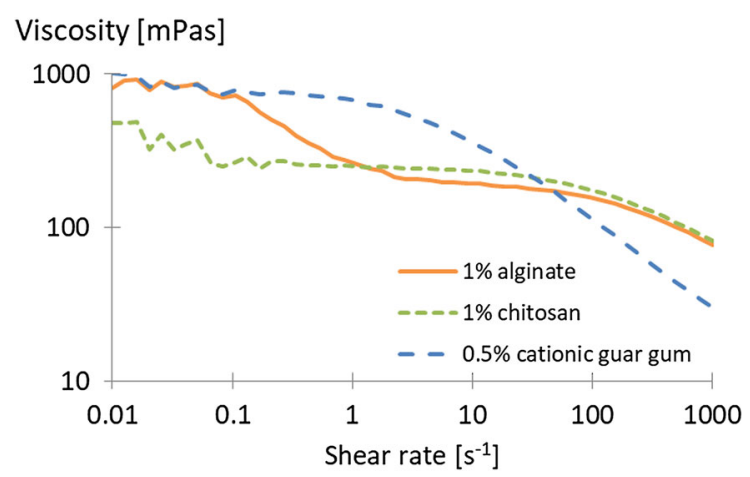

Fig. 2 The measured viscosity curves of the polysaccharides in solution

\section{Papermaking procedure}

Handsheets were formed on a 125 mesh wire in a $165 \mathrm{~mm} \times 165 \mathrm{~mm}$ laboratory sheet former. The handsheets were prepared without recirculation of white water. The aimed grammage of all of the handsheets was $100 \mathrm{~g} / \mathrm{m}^{2}$. The handsheets were couched from the wire by pressing, and stored wet (solids content 26-28\%) between wet blotter papers in sealed plastic bags at $5{ }^{\circ} \mathrm{C}$ until further use.

The polysaccharide solutions were sprayed onto the top side of the wet sheets using a commercial, highvolume, low-pressure (HVLP) gravity feed air spray gun. The top side of the wet sheets were sprayed with polysaccharide amounts corresponding to of 2 and $4 \%$ o.d. polysaccharides based on dry paper weight. A wet sheet was placed on a rigid plastic plate on top of a gravimetric scale. The targeted amount of solution was adjusted by controlling the wet weight of the sheet after spraying. Reference sheets were sprayed with an equivalent amount of cold tap water. The sprayed samples were placed on a vacuum box covered with a fabric wire; a vacuum level of approximately 5-10 kPa was applied beneath the sprayed sheet. The aim of the vacuum treatment was to remove excess water from the sheets and aid the penetration of the polysaccharides into the wet fiber network. Ten handsheets were sprayed for each trial point; five sheets were subjected to restrained drying, and five sheets were subjected to unrestrained drying.

Restrained drying: the sheets treated with polysaccharide solutions were dried on a plate with a blotter, strapped into a drying frame. Unrestrained drying: the treated handsheets were dried in specially built drying frames, between two polymer forming wires with a gap of approximately $3 \mathrm{~mm}$ to allow for paper shrinkage during drying, while simultaneously preventing severe cockling and curling of the sheets. Both, restrained and unrestrained drying methods were performed under standard testing conditions (EN ISO 5269-1:2005E). None of the sheets were wetpressed prior to drying.

\section{Paper testing}

The basis weight of the paper samples was determined according to ISO 536:1995. The thickness was determined according to ISO 534:1998, and the density was determined based on the measured values of the basis 
Table 1 The measured fiber properties of unrefined and low-consistency refined softwood kraft pulp

(l) Length-averaged values

\begin{tabular}{lcc}
\hline & Unrefined $\left({ }^{\circ} \mathrm{SR} 12\right)$ & ProLab refined $\left({ }^{\circ} \mathrm{SR} 25\right)$ \\
\hline Fiber length $(\mathrm{l})(\mathrm{mm})$ & 1.83 & 1.83 \\
Fines $(1)(\%)$ & 2.45 & 2.90 \\
Fiber width $(\mu \mathrm{m})$ & 28.5 & 29.7 \\
Cell wall thickness $(\mu \mathrm{m})$ & 6.2 & 7.6 \\
Curl $(\%)$ & 15.3 & 14.5 \\
\hline
\end{tabular}

weight and thickness. The air permeability of the papers was determined with a Lorentzen \& Wettre, L\&W Air permeance tester according to ISO 5636-3. The mechanical properties (i.e. tensile index, stretch, work, and tensile stiffness) of the paper sheets were determined with a Lloyd tensile tester (AMETEK, USA), in accordance with ISO 5270:1998. The straining speed was $100 \mathrm{~mm} / \mathrm{min}$ in the tensile measurements. Paper samples were conditioned and all testing of the samples took place at a temperature of $23{ }^{\circ} \mathrm{C}$ and at $50 \%$ relative humidity (EN ISO 5269-3). Eight parallel measurements were performed. The paper shrinkage during restrained and unrestrained drying was measured and calculated according to the procedure described by Vishtal and Retulainen (2014a). Shrinkages of restrained and unrestrained dried sheets were measured by applying marker holes with known separations in the wet sheets as described by Khakalo et al. (2017b).

\section{$2 D$ formability tests}

The formability strain and force of the paper samples were measured using a 2D-formability tester at VTT. A detailed description of the measurement procedure and set-up is available in literature (Vishtal and Retulainen 2014a). In this study, the velocity of the forming press was $10 \mathrm{~mm} / \mathrm{s}$ and the width of the paper sample was $20 \mathrm{~mm}$. The paper samples were set in the tester so that the sprayed surface was not in contact with the heated press. The 2D formability tests were repeated seven times for each trial point.

\section{Scanning electron microscopy}

Scanning electron microscopy (SEM) was performed using a JEOL JSM-IT100 instrument. Images were produced in low-vacuum mode (40 Pa) using backscattered electrons. The accelerating voltage was $10 \mathrm{kV}$.

\section{Results and discussions}

Mechanical testing of model films from the polysaccharides

Model films were prepared from the different polysaccharides with added sorbitol as softener (50\%). Addition of sorbitol was required in order to successfully prepare polysaccharide films, since these type of films otherwise become too brittle to handle, and crack during drying. It has previously been reported that addition of $50 \%$ glycerol as plasticizer was needed when model films were prepared from agar and $\kappa$ carrageenan in order to avoid brittleness of the films (Rhim 2012). It has also been reported that the tensile strength and Young's modulus of oat spelt arabinoxylan films was slightly higher with sorbitol than with glycerol at high dosages (Mikkonen et al. 2009). Therefore, sorbitol was the softener of choice in the current experimental series.

The model films from the different polysaccharides were subjected to mechanical testing. It was immediately evident that the different polysaccharides gave films with very different characteristics (Fig. 3). Alginate gave the strongest model films, with a

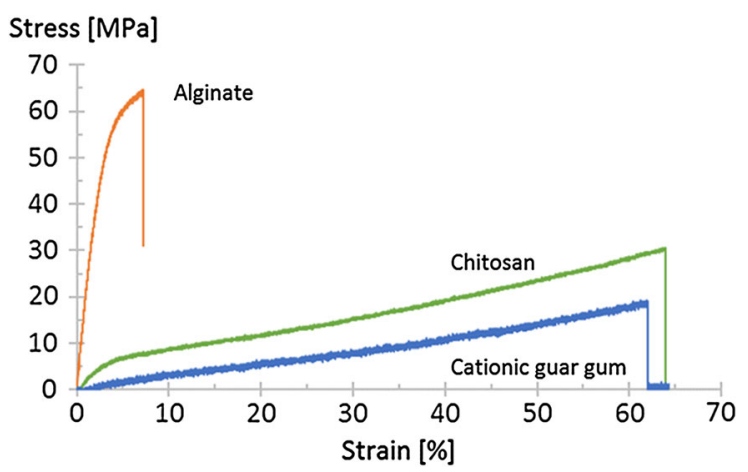

Fig. 3 Examples of the stress-strain curves of polysaccharide model films. To all of the displayed examples, $50 \%$ sorbitol had been added as softener 
strength value of $63 \mathrm{MPa}$ (Table 2). The elastic modulus of the alginate film was also quite high, with a value of $2 \mathrm{GPa}$. However, the strain at break of the alginate film was only $7 \%$. Other studies have reported that the tensile strength of films made from sodium alginate $+40 \%$ glycerol was $12 \mathrm{MPa}$, their elastic modulus roughly $170 \mathrm{MPa}$, and their strain at break just below 30\% (Yoo and Krochta 2011). It is known that there are quite large variations between available alginate sources and/or qualities; there are variations in the ratio between mannosyluronic and gulosyluronic units, as well as the length of each block depending on source (Lee and Mooney 2012). These model films from alginate had quite extraordinarily high strength and stiffness values.

Chitosan gave significantly weaker model films than alginate, and the elastic modulus was also much lower (Table 2). However, the strain at break of the chitosan films was 55\%. Additionally, the stress-strain curves of the chitosan films revealed a distinctive initial stiffness of the films prior to the plastic region of the curves (Fig. 3). The chitosan films could be strained almost seven times further than the corresponding alginate films. Cationic guar gum gave even weaker model films with extremely low elastic modulus (Table 2). The strain at break of films from cationic guar gum was quite high, much like with chitosan. The cationic guar gum films lacked the initial stiffness of chitosan.

These results indicated that there is an inverse relationship between tensile strength and strain at break; stronger polysaccharide films tend to have lower strain at break values. It is known that the mechanical properties of model films from polysaccharides are heavily influenced by the properties of the compounds and their packing possibilities, as well as the amount and type of plasticizer (Arvanitoyannis and Biliaderis 1999; Mikkonen et al. 2009; Yoo and Krochta 2011). After these initial results, the main focus of the main study was to determine whether or not the characteristic tensile properties of the different polysaccharides were transferable to a fiber network. The applications were performed as spray additions of the polysaccharides in solution onto pre-formed, wet handsheets.

Spray addition of polysaccharides onto wet handsheets

Wet handsheets were sprayed with the different polysaccharide solutions to dosage levels of 2 or $4 \mathrm{wt} \%$. The polysaccharides were alginate, chitosan and cationic guar gum. Sorbitol, 20 and $30 \%$ calculated on polysaccharide dry weight, was added to the solutions before spraying as softener.

The tensile index of the handsheets after restrained drying were plotted as a function of their density (Fig. 4). The tensile index of the sprayed reference sheet was $57.2 \mathrm{Nm} / \mathrm{g}$. All of the polysaccharides increased the tensile index and density of the sheets after restrained drying (Table 3). Cationic guar gum increased the tensile index by $7.2-11.0 \mathrm{Nm} / \mathrm{g}$, while chitosan resulted in increases of $5.7-19.1 \mathrm{Nm} / \mathrm{g}$. Alginate resulted in larger increases in tensile index, between 17.5 and $30.9 \mathrm{Nm} / \mathrm{g}$, reaching a maximum value of $88.1 \mathrm{Nm} / \mathrm{g}$ with $2 \%+30 \%$ sorbitol. The overall increases in tensile index after restrained drying followed a similar pattern as the results from the tensile tests of the polysaccharide model films; alginate formed the strongest films, while films from chitosan and cationic guar gum were significantly weaker. In previous studies, spray addition of $4 \%$ gelatin + cross-linker or spray addition of $4 \%$ gelatin, $4 \%$ agar + cross-linker was required in order to surpass $80 \mathrm{Nm} / \mathrm{g}$ after restrained drying (Vishtal et al. 2015).

The tensile index of the handsheets after unrestrained drying were plotted as a function of their

Table 2 The determined values of tensile strength, elastic modulus, and strain at break of model films from the polysaccharides

\begin{tabular}{llrr}
\hline Polysaccharide film & Tensile strength (MPa) & E-modulus (MPa) & Strain at break (\%) \\
\hline Alginate $+50 \%$ sorbitol & 63 & 2045 & 7 \\
Chitosan $+50 \%$ sorbitol & 25 & 203 & 55 \\
Cationic guar gum $+50 \%$ sorbitol & 18 & 67 & 47 \\
\hline
\end{tabular}

$50 \%$ sorbitol was added as softener 
Fig. 4 Tensile index $(\mathrm{Nm} /$ g) versus density $\left(\mathrm{kg} / \mathrm{m}^{3}\right)$ of handsheets sprayed with the different polysaccharide solutions. The paper properties were measured after restrained $(\mathrm{R})$ and unrestrained (UR) drying. Ref reference samples. The average values with their standard deviations are shown

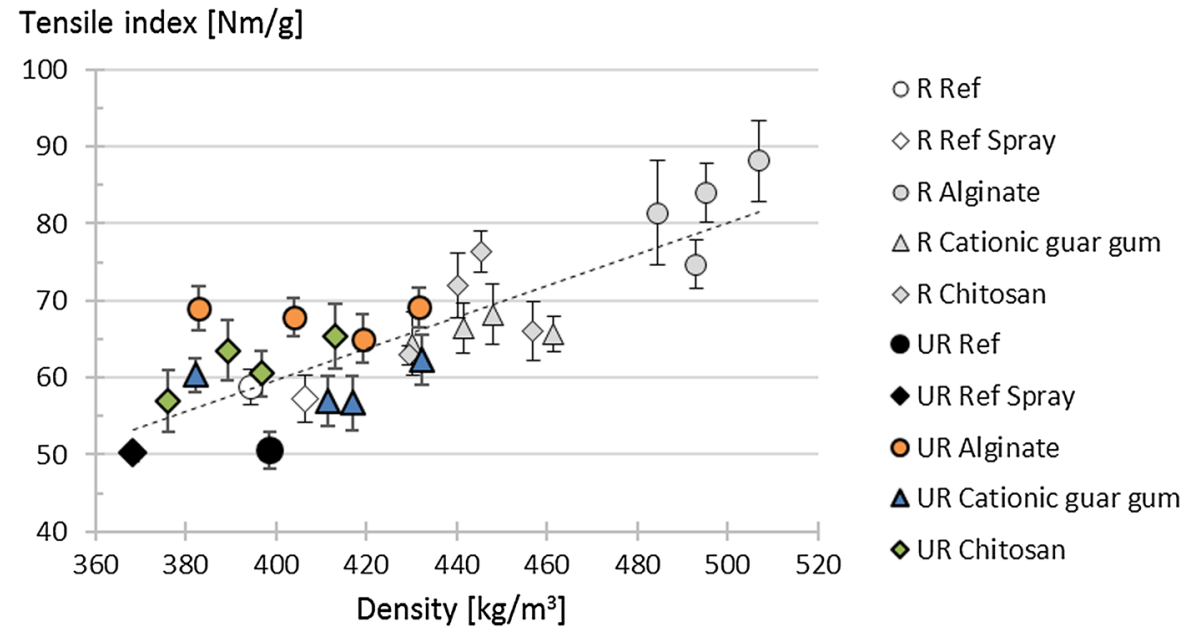

Table 3 The mechanical properties of handsheets after restrained drying

\begin{tabular}{|c|c|c|c|c|c|c|c|c|c|c|}
\hline \multirow[t]{2}{*}{ Restrained drying } & \multirow[t]{2}{*}{ Density $\mathrm{kg} / \mathrm{m}^{3}$} & \multicolumn{2}{|c|}{$\begin{array}{l}\text { Tensile } \\
\text { index }\end{array}$} & \multicolumn{2}{|l|}{$\begin{array}{l}\text { Tensile } \\
\text { stiffness }\end{array}$} & \multicolumn{2}{|c|}{$\begin{array}{l}\text { Strain at } \\
\text { break }\end{array}$} & \multirow{2}{*}{$\begin{array}{l}\text { 1D } \\
\text { shrinkage } \\
\%\end{array}$} & \multicolumn{2}{|c|}{$\begin{array}{l}\text { Air } \\
\text { permeability }\end{array}$} \\
\hline & & $\mathrm{Nm} / \mathrm{g}$ & $\mathrm{s}$ & $\mathrm{kNm} / \mathrm{g}$ & $\mathrm{s}$ & $\%$ & $\mathrm{~s}$ & & $\mathrm{~mL} / \mathrm{min}$ & $\mathrm{s}$ \\
\hline Reference & 394.5 & 58.8 & 2.3 & 4.2 & 0.8 & 6.7 & 0.6 & nd & 2868 & 367 \\
\hline Reference-sprayed & 406.4 & 57.2 & 3.1 & 4.4 & 0.2 & 5.8 & 0.6 & 1.0 & 4020 & 380 \\
\hline $2 \%$ Alginate $(+20 \%$ sorbitol $)$ & 493.1 & 74.7 & 3.1 & 5.1 & 0.2 & 5.2 & 0.3 & 0.7 & 503 & 28 \\
\hline $2 \%$ Alginate $(+30 \%$ sorbitol $)$ & 507.0 & 88.1 & 5.2 & 5.8 & 0.1 & 5.4 & 0.5 & 0.2 & 413 & 50 \\
\hline $4 \%$ Alginate $(+20 \%$ sorbitol $)$ & 495.3 & 84.0 & 3.8 & 5.6 & 0.2 & 5.3 & 0.4 & 0.1 & 276 & 58 \\
\hline $4 \%$ Alginate $(+30 \%$ sorbitol $)$ & 484.6 & 81.4 & 6.8 & 5.5 & 0.2 & 5.0 & 0.7 & 0.2 & 382 & 53 \\
\hline $2 \%$ Cationic guar gum $(+20 \%$ sorbitol $)$ & 441.5 & 66.4 & 3.2 & 4.3 & 0.4 & 6.0 & 0.5 & 1.2 & 2148 & 229 \\
\hline $2 \%$ Cationic guar gum $(+30 \%$ sorbitol $)$ & 430.3 & 64.4 & 4.1 & 4.2 & 0.1 & 6.1 & 0.4 & 1.8 & 2366 & 347 \\
\hline $4 \%$ Cationic guar gum $(+20 \%$ sorbitol $)$ & 448.0 & 68.2 & 3.9 & 5.2 & 0.1 & 4.9 & 0.4 & 1.1 & 2135 & 321 \\
\hline $4 \%$ Cationic guar gum $(+30 \%$ sorbitol $)$ & 461.5 & 65.6 & 2.3 & 4.3 & 0.3 & 6.0 & 0.3 & 1.1 & 1805 & 193 \\
\hline $2 \%$ Chitosan $(+20 \%$ sorbitol $)$ & 445.3 & 76.3 & 2.6 & 4.3 & 0.2 & 6.6 & 0.4 & nd & 2808 & 283 \\
\hline $2 \%$ Chitosan $(+30 \%$ sorbitol $)$ & 429.6 & 62.9 & 1.2 & 3.8 & 0.3 & 6.1 & 0.5 & 1.3 & 2660 & 230 \\
\hline $4 \%$ Chitosan $(+20 \%$ sorbitol $)$ & 457.0 & 66.0 & 3.8 & 4.9 & 0.1 & 4.7 & 0.3 & nd & 3180 & 169 \\
\hline $4 \%$ Chitosan $(+30 \%$ sorbitol $)$ & 440.3 & 71.9 & 4.2 & 4.8 & 0.1 & 5.0 & 0.4 & 05 & 3212 & 314 \\
\hline
\end{tabular}

The average values, as well as their standard deviations (s) are reported. The additions were calculated as wt\% of o.d. pulp

density (Fig. 4). The density of the handsheets was significantly lower due to the considerable paper shrinkage during the drying process. It is known that unrestrained drying alters the mechanical properties of paper quite significantly (see e.g. Strand et al. 2017). When comparing the untreated reference sheets with reference sheets sprayed with tap water, it was seen that the spraying procedure alone lowered the density of the handsheets (Fig. 4). All of the polysaccharide additions increased the tensile index of the sheets after unrestrained drying. Alginate resulted in the largest increases in tensile index also in this case, but the differences to cationic guar gum and chitosan were quite small. It was previously reported that spray addition of 2 or $4 \%$ agar was only able to increase the tensile index of paper by approximately $3 \mathrm{Nm} / \mathrm{g}$ after wet-pressing, unless a cross-linker was added (Vishtal and Retulainen 2014a). Additions of 4\% agar + 
cross-linker gave similar tensile index values as addition of $2 \%$ alginate. Similarly, it has been reported that spray addition of $4 \%$ gelatin increased the tensile index of paper from 59.3 to $70.3 \mathrm{Nm} / \mathrm{g}$ after wetpressing and unrestrained drying, i.e. by $11 \mathrm{Nm} / \mathrm{g}$ (Khakalo et al. 2014). The tensile index could, once again, be increased further by addition of glutaraldehyde as a cross-linker. As a comparison, addition of $2 \%$ alginate in the current study increased the tensile index of the papers by $18.9 \mathrm{Nm} / \mathrm{g}$ without wetpressing, which is quite substantial. The addition of $2 \%$ alginate resulted in a similar tensile index values as sequential addition of $4 \%$ gelatin and $4 \%$ agar after unrestrained drying (Vishtal et al. 2015).

Plotting the tensile index versus density of papers after restrained and unrestrained drying revealed an almost linear dependency (Fig. 4). It is known that the relative bonded area is heavily linked to paper density, and that there is a strong relationship between relative bonded area and tensile strength (Page 1969). A linear dependency have been shown to exist between the relative bonded area and sheet density using bleached softwood kraft pulps of different mixtures of springwood and summerwood fibers (Retulainen and Ebeling 1993). A linear dependency has also been shown between the determined BET-area of papers and their tensile index; the tensile index increased as the amount of unbound areas in the papers decreased (Lindström et al. 2016). Even for the current results, where the density ranges between 368 and $507 \mathrm{~kg} / \mathrm{m}^{3}$ due to the different additives and drying techniques, a somewhat linear dependency between tensile index and paper density could be seen.

The strain at break of the handsheets were plotted as a function of their tensile stiffness (Fig. 5). After restrained drying, the strain at break of the handsheets were similar to, or lower than, the level of the reference sheets. Increases in strain at break of papers after restrained drying have previously been reported after addition of agar and gelatin; the highest reported value was approximately $7 \%$ after with of $4 \%$ gelatin, 4\% agar + cross-linker (Vishtal et al. 2015). In the current study, all of the polysaccharides resulted in increased tensile stiffness values of the handsheets after restrained drying. The largest increases in were seen with alginate, while cationic guar gum or chitosan resulted in less pronounced increases (Table 3). The highest stiffness value obtained was $5.8 \mathrm{kNm} / \mathrm{g}$ with $2 \mathrm{wt} \%$ alginate $+30 \%$ sorbitol as softener, i.e. an increase of $1.4 \mathrm{kNm} / \mathrm{g}$ from the sprayed reference. As a comparison, a tensile stiffness of $6.4 \mathrm{kNm} / \mathrm{g}$ was previously achieved with wet-end additions of carboxymethyl cellulose in combination with a cationic starch (Strand et al. 2017).

The strain at break after unrestrained drying increased moderately with cationic guar gum or chitosan, while the largest increases were seen with alginate (Fig. 5). The largest strain at break value, i.e. $11.3 \%$, was obtained with $2 \mathrm{wt} \%$ alginate +20 or $30 \%$ sorbitol (Table 4). It has been reported that 2 or $4 \%$ agar also increased the strain at break of paper by approximately $2 \%$ after unrestrained drying (Vishtal and Retulainen 2014a). Addition of $4 \%$ gelatin also increased the strain at break of papers after unrestrained drying by about $2 \%$, while further addition of $0.5 \%$ cross-linker resulted in an increase of $4.4 \%$ (Khakalo et al. 2014). Sequential additions of $4 \%$ gelatin and $4 \%$ agar + cross-linker were able to achieve strain at break increases of approximately $5 \%$, but the dosage levels were quite high in this study (Vishtal et al. 2015). In the current study, all of the tensile stiffness values of the sheets were similar to, or lower than, the reference value of $2.4 \mathrm{kNm} / \mathrm{g}$ after unrestrained drying. Alginate, chitosan, or cationic guar gum had slight to no effect on the stiffness of handsheets after unrestrained drying, even though noticeable changes were seen in strain at break and tensile index. It has been previously reported that $4 \%$ gelatin increased the tensile stiffness slightly of the paper after unrestrained drying, while including a cross-linker made this effect more pronounced (Khakalo et al. 2014). Sequential addition of gelatin and agar resulted in increased stiffness values, from $75 \mathrm{kN} / \mathrm{m}$ up to approximately $90 \mathrm{kN} / \mathrm{m}$, after unrestrained drying (Vishtal et al. 2015). It was noted that the results from the preliminary study of polysaccharide model films were not directly transferable to the fiber network after unrestrained drying; chitosan or cationic guar gum did not increase the strain at break significantly, while alginate instead resulted in higher values.

The 2D formability strain of the handsheets after unrestrained drying was tested at 23 and $90{ }^{\circ} \mathrm{C}$. The reference sheets could strain approximately $10 \%$ before breaking in the $2 \mathrm{D}$ tests (Fig. 6), i.e. about $1 \%$ further than in regular tensile testing. When comparing the reference with the reference samples of previously published 2D formability tests, it was clear 
Fig. 5 Tensile stiffness $(\mathrm{kNm} / \mathrm{g})$ versus strain at break $(\%)$ of handsheets sprayed with the different polysaccharide solutions. The paper properties were measured after restrained (R) and unrestrained (UR) drying. The average values with their standard deviations are shown
Tensile stiffness $[\mathrm{kNm} / \mathrm{g}]$

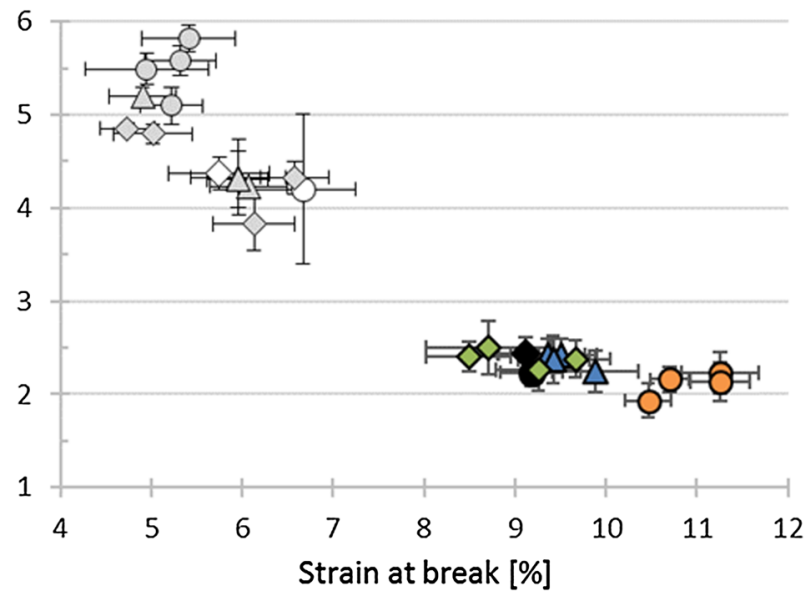

OR Ref

$\diamond$ R Ref Spray

o R Alginate

$\triangle R$ Cationic guar gum

$\diamond \mathrm{R}$ Chitosan

- UR Ref

- UR Ref Spray

o UR Alginate

$\Delta$ UR Cationic guar gum

$\diamond$ UR Chitosan

Table 4 The mechanical properties of handsheets after unrestrained drying

\begin{tabular}{|c|c|c|c|c|c|c|c|c|c|c|}
\hline \multirow[t]{2}{*}{ Unrestrained drying } & \multirow[t]{2}{*}{ Density $\mathrm{kg} / \mathrm{m}^{3}$} & \multicolumn{2}{|c|}{$\begin{array}{l}\text { Tensile } \\
\text { index }\end{array}$} & \multicolumn{2}{|l|}{$\begin{array}{l}\text { Tensile } \\
\text { stiffness }\end{array}$} & \multicolumn{2}{|c|}{$\begin{array}{l}\text { Strain at } \\
\text { break }\end{array}$} & \multirow{2}{*}{$\begin{array}{l}\text { 1D shrinkage } \\
\%\end{array}$} & \multicolumn{2}{|c|}{$\begin{array}{l}\text { Air permeabi } \\
\text { lity }\end{array}$} \\
\hline & & $\begin{array}{l}\mathrm{Nm} / \\
\mathrm{g}\end{array}$ & $\mathrm{s}$ & $\mathrm{kNm} / \mathrm{g}$ & $\mathrm{s}$ & $\%$ & $\mathrm{~s}$ & & $\mathrm{~mL} / \mathrm{min}$ & $\mathrm{s}$ \\
\hline Reference & 398.6 & 50.6 & 2.4 & 2.2 & 0.1 & 9.2 & 0.3 & 4.3 & 2394 & 398 \\
\hline Reference-sprayed & 368.4 & 50.2 & 1.1 & 2.4 & 0.2 & 9.1 & 0.3 & 4.3 & 2380 & 129 \\
\hline $2 \%$ Alginate $(+20 \%$ sorbitol $)$ & 431.7 & 69.1 & 2.5 & 2.2 & 0.2 & 11.3 & 0.4 & 5.4 & 556 & 54 \\
\hline $2 \%$ Alginate $\left(+30^{\circ} \%\right.$ sorbitol $)$ & 382.8 & 69.0 & 2.9 & 2.1 & 0.2 & 11.3 & 0.3 & 5.3 & 187 & 76 \\
\hline $4^{\circ} \%$ Alginate $(+20 \%$ sorbitol $)$ & 419.2 & 65.0 & 3.2 & 1.9 & 0.2 & 10.5 & 0.3 & 4.8 & 377 & 113 \\
\hline $4 \%$ Alginate $(+30 \%$ sorbitol $)$ & 404.0 & 67.9 & 2.5 & 2.2 & 0.1 & 10.7 & 0.2 & 4.8 & 316 & 96 \\
\hline $2 \%$ Cationic guar gum $(+20 \%$ sorbitol $)$ & 416.9 & 56.7 & 3.5 & 2.2 & 0.2 & 9.9 & 0.5 & 4.0 & 2272 & 319 \\
\hline $2 \%$ Cationic guar gum $(+30 \%$ sorbitol $)$ & 432.3 & 62.3 & 3.3 & 2.4 & 0.2 & 9.5 & 0.3 & 4.0 & 2356 & 128 \\
\hline $4 \%$ Cationic guar gum $(+20 \%$ sorbitol $)$ & 411.6 & 56.9 & 3.2 & 2.4 & 0.2 & 9.4 & 0.6 & 3.9 & 2083 & 169 \\
\hline $4 \%$ Cationic guar gum $(+30 \%$ sorbitol $)$ & 382.2 & 60.3 & 2.3 & 2.4 & 0.3 & 9.4 & 0.4 & 4.0 & 2218 & 427 \\
\hline $2 \%$ Chitosan $(+20 \%$ sorbitol $)$ & 413.2 & 65.4 & 4.2 & 2.4 & 0.2 & 8.5 & 0.5 & 4.0 & 3010 & 283 \\
\hline $2 \%$ Chitosan $(+30 \%$ sorbitol $)$ & 389.2 & 63.5 & 3.9 & 2.5 & 0.3 & 8.7 & 0.7 & 4.0 & 3528 & 194 \\
\hline $4 \%$ Chitosan $(+20 \%$ sorbitol $)$ & 396.8 & 60.5 & 3.0 & 2.4 & 0.2 & 9.7 & 0.4 & 3.4 & 2774 & 390 \\
\hline $4 \%$ Chitosan $(+30 \%$ sorbitol $)$ & 376.2 & 56.9 & 4.0 & 2.3 & 0.2 & 9.3 & 0.5 & 3.6 & 2724 & 274 \\
\hline
\end{tabular}

The average values, as well as their standard deviations (s) are reported. The additions were calculated as wt $\%$ of o.d. pulp

that the base paper in the current study had a lower extensibility compared to in previous studies, i.e. $10 \%$ compared to 12-13\% (Vishtal and Retulainen 2014a; Khakalo et al. 2014; Vishtal et al. 2015). In the current study, only low-consistency (LC) pulp refining had been used, while a combination of high-consistency (HC) and LC refining had been used in the other studies. It is known that combination of $\mathrm{HC}$ and $\mathrm{LC}$ refining is a good strategy to produce paper with high elongation potential and with high tensile strength simultaneously (Zeng et al. 2013).

Addition of cationic guar gum or chitosan resulted in very slight increases in 2D formability. Alginate, however, resulted in significant increases in $2 \mathrm{D}$ formability, with values between 12.3 and $13.1 \%$, i.e. increases of $2.2-3 \%$, at room temperature. 
Fig. 6 The $2 \mathrm{D}$ formability (\%) at $23{ }^{\circ} \mathrm{C}$ and $90{ }^{\circ} \mathrm{C}$ of handsheets sprayed with the different polysaccharide solutions. The paper properties were measured after unrestrained drying. The average values with standard deviations are shown. Alg alginate, $C$-gg cationic guar gum, Chit chitosan. The amount of added sorbitol is also shown in the $\mathrm{x}$-axis legends

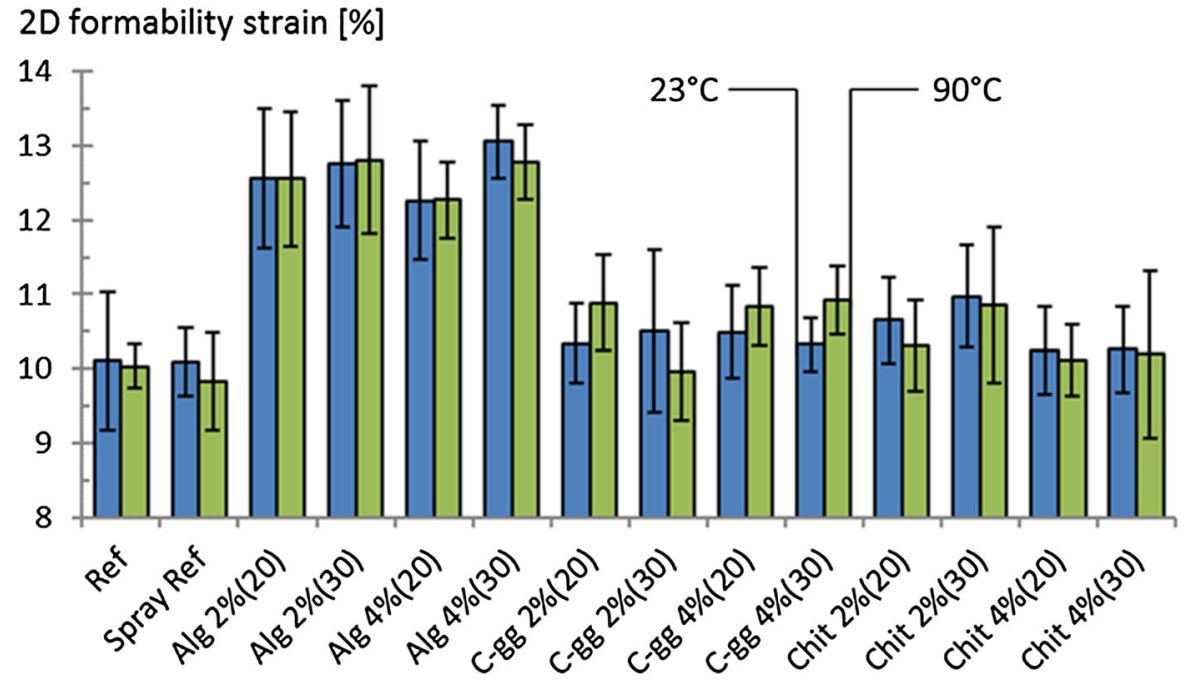

Alginate increased the $2 \mathrm{D}$ formability to a similar extent as $4 \%$ gelatin, and $4 \%$ gelatin + cross-linker, while outperforming addition of $4 \%$ agar (Vishtal and Retulainen 2014a; Khakalo et al. 2014). However, it has also been reported that addition of $4 \%$ gelatin only increased the 2D formability by approximately $0.5 \%$ at room temperature after unrestrained drying, highlighting some inconsistencies (Vishtal et al. 2015). With alginate, cationic guar gum or chitosan, there were no significant differences in the formability of the sheets as a function of temperature. It has previously been reported that the $2 \mathrm{D}$ formability of paper sprayed with agar and/or gelatin does increase with increasing temperature (Vishtal and Retulainen 2014a; Khakalo et al. 2014; Vishtal et al. 2015).

In order to better understand the previously presented results, the measured paper shrinkages were plotted against their corresponding strain at break values after restrained and unrestrained drying (Fig. 7). It was seen that also the handsheets dried under restraint between blotters had shrunk to some extent; between 0.1 and $1.8 \%$ 1D shrinkage was measured (Table 3). Even limited paper shrinkage during restrained drying will affect the paper properties, by enhancing the strain at break and lowering the tensile stiffness to some extent. In a previously published study, it was seen that a strain at break of $6.4 \%$ could be considered the upper limit of elongation potential from strength increases alone without paper shrinkage (Strand et al. 2017). In a previously reported refining study, it was seen that the strain at break of papers leveled off at about 5\% with increasing refining energy, when the drying shrinkage of the sheets had been minimized (Strand et al. 2018). Also shrinkage during restrained drying needs to be considered and measured when dealing with strain at break values surpassing $6.5 \%$, to ensure that the high values are not a function of unexpected drying shrinkage. Strain at break values of up to $7 \%$ after restrained drying have been reported for sheets sprayed with $4 \%$ gelatin, $4 \%$ agar + cross-linker, but the paper shrinkage during restrained drying was not reported (Vishtal et al. 2015). When all of the measured 1D shrinkages were combined with their corresponding strain at break values, an almost linear correlation emerged. The correlation indicated that handsheets without any shrinkage should be able to strain $4.6 \%$, which is very close to previously reported values for this pulp after $135 \mathrm{kWh} / \mathrm{t}$ of LC-refining (Strand et al. 2018). A linear trend between strain at break and drying shrinkage during unrestrained drying has previously been presented, as a function of sprayed amount of agar (Vishtal and Retulainen 2014a). The current study extends the linear correlation towards lower shrinkage values also.

The 1D shrinkage after unrestrained drying was significantly larger than after restrained drying (Table 4). The 1D shrinkage of the reference sheets was $4.3 \%$. Cationic guar gum and chitosan decreased the shrinkage slightly, and had quite limited effects on the strain at break of the sheets (Fig. 7). The tendency for cationic polysaccharides to decrease paper 


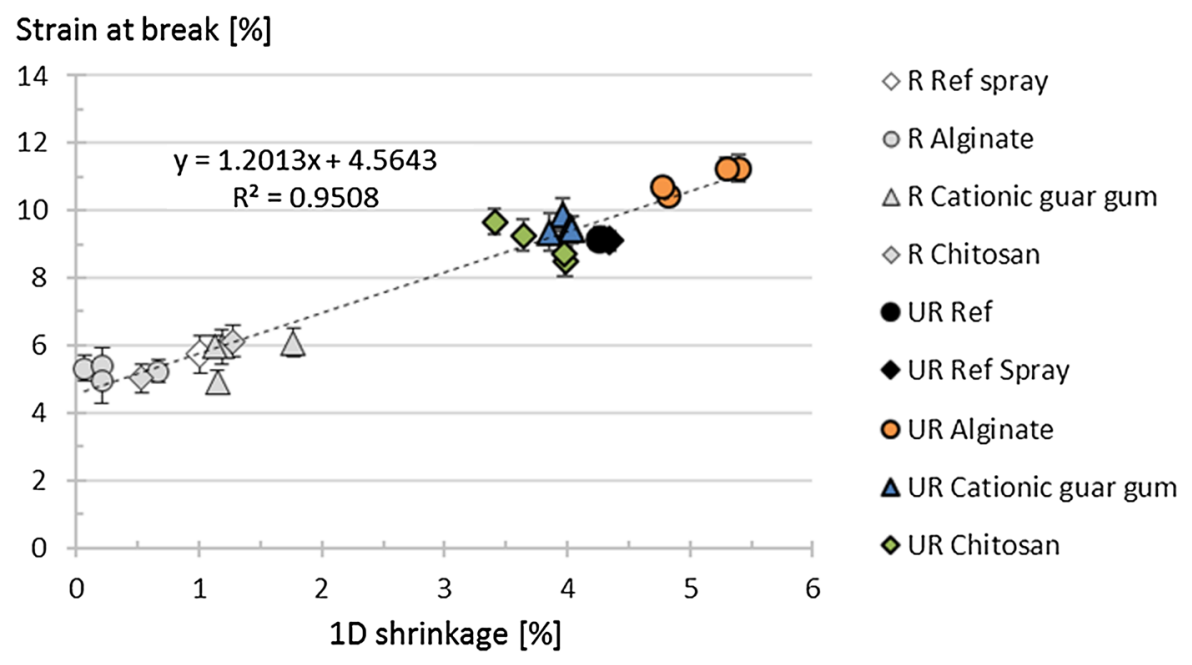

Fig. 7 Strain at break (\%) versus 1D shrinkage (\%) of handsheets sprayed with the different polysaccharide solutions. The paper properties were measured after restrained (R) and unrestrained (UR) drying. The average values with standard deviations are shown

shrinkage has previously been studied and reported (Strand et al. 2017). Alginate was the only tested polysaccharide that actively increased paper shrinkage during unrestrained drying, which lead to noticeably higher strain at break values of the handsheets.

The air permeability of the handsheets was measured after restrained and unrestrained drying. After restrained drying, the water spraying had increased the air permeability from 2868 to $4020 \mathrm{~mL} / \mathrm{min}$ (Table 3). The large influence of the spraying procedure was, however, not visible after unrestrained drying (Table 4). After restrained drying, all of the polysaccharide additions resulted in decreased air permeability values (Fig. 8). Alginate lowered the air permeability values of the handsheets significantly. Chitosan or cationic guar gum did not result in similar decreases. A drastic decrease in air permeability has previously been also reported after addition of agar onto wet sheets; the value decreased by approximately 84\% (Vishtal and Retulainen 2014a). In the same study, it was reported that a surface film of agar could be useful in grease-barrier applications due to the hydrophilic nature of the polysaccharide and the dense structure of the surface.

The sprayed top sides of the different handsheets were imaged using a scanning electron microscope
Fig. 8 The air permeability ( $\mathrm{mL} / \mathrm{min})$ of handsheets sprayed with the different polysaccharide solutions. The permeability values were measured after restrained and unrestrained drying. The average values with standard deviations are shown. Alg alginate, $C-g g$ cationic guar gum, Chit chitosan. The amount of added sorbitol is also shown in the $\mathrm{x}$-axis legends

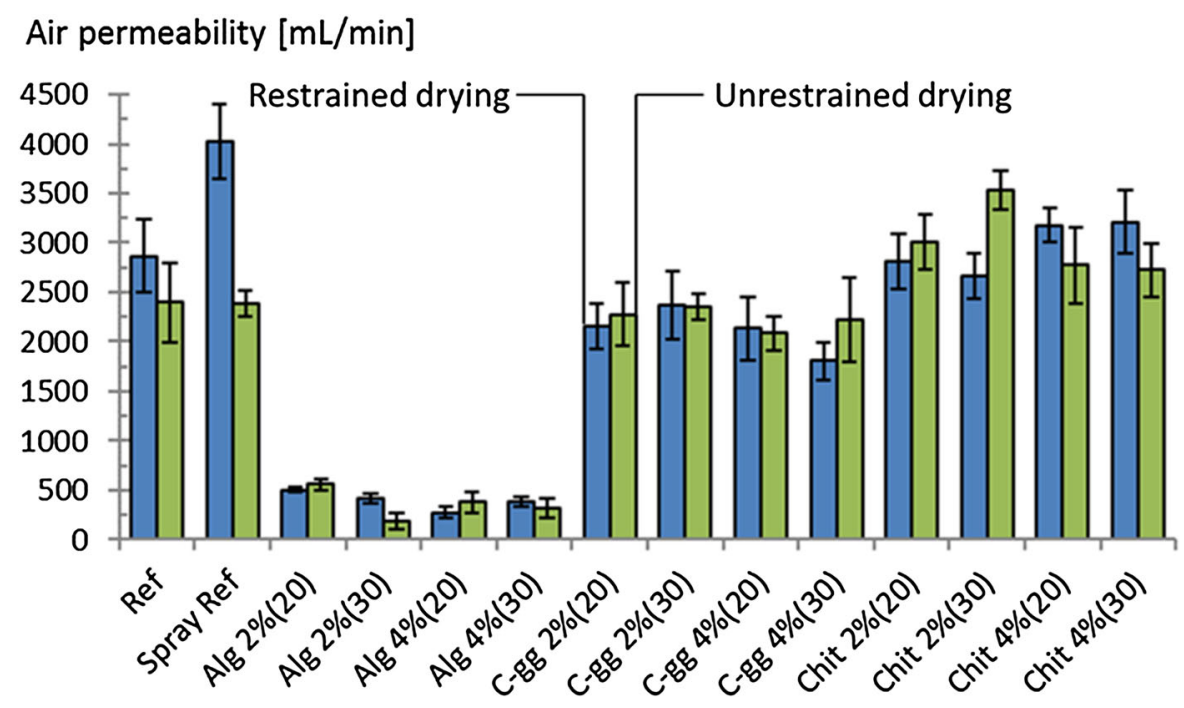


(SEM). It was seen that the handsheets had a much denser surface structure with alginate, compared to with cationic guar gum or chitosan (Fig. 9). The alginate seemed to fill out some of the roughness of the paper surface, which also lowered the air permeability of the fiber network significantly. This was similar to the previously reported effect of agar (Vishtal and Retulainen 2014a). The available results indicate that anionic additives may form a film on top of the sheet after spray addition, while cationic additives may migrate more freely throughout the fiber network, once saturated. This is also in agreement with previous findings that iminated amphiphilic galactoglucomannans formed a film on top of the paper after spray addition, while cationic galactoglucomannans were able to penetrate deeper into the fiber network during impregnation (Lindqvist et al. 2014). The formation of an alginate film on the top side of the paper resulted in enhanced paper shrinkage, which significantly increased the strain at break and 2D formability strain after unrestrained drying. The shrinkage of the wet alginate film during drying was most likely transferred to the rest of the fiber network causing enhanced paper shrinkage, much like the reported effect of agar (Vishtal and Retulainen 2014a).

\section{Conclusions}

Model polysaccharide films were prepared from alginate, cationic guar gum, or chitosan. Alginate resulted in very strong and stiff films with low strain at break values, while cationic guar gum and chitosan resulted in significantly weaker and softer films with high strain at break values. The different polysaccharide solutions were sprayed onto wet handsheets, and
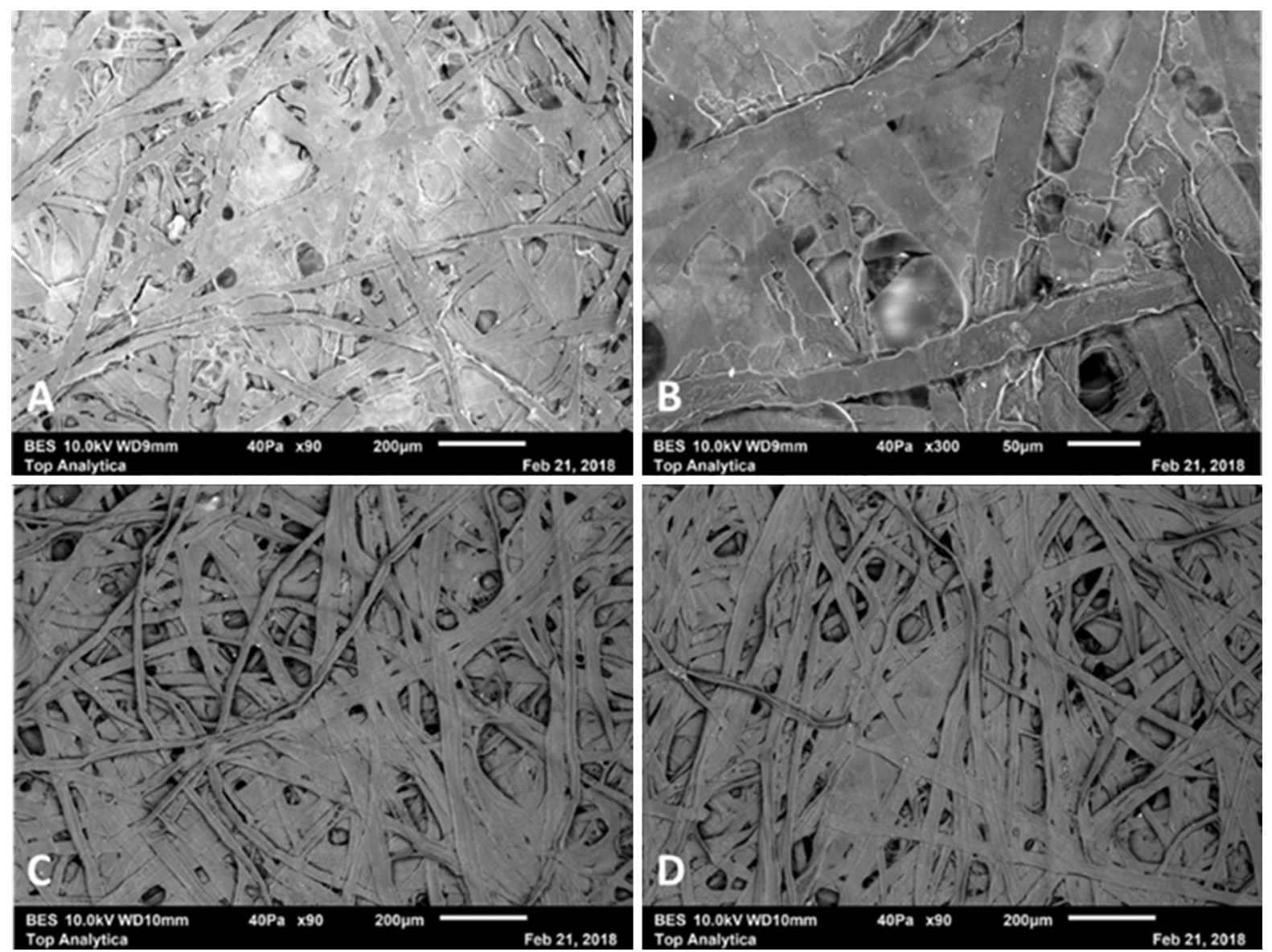

Fig. 9 SEM micrographs of the top surfaces of handsheets sprayed with alginate (A, B), cationic guar gum (C), and chitosan (D). All of these handsheets were sprayed with $2 \%$ polysaccharide with addition of $20 \%$ sorbitol, and subjected to restrained drying 
the paper properties were measured after restrained and unrestrained drying. Alginate resulted in stiffer and stronger paper than the other tested polysaccharides after restrained drying. Alginate also increased the $2 \mathrm{D}$ formability strain of papers after unrestrained drying to a higher extent. Addition of alginate resulted in the formation of a film on the topside of the paper, which decreased the air permeability of the paper significantly and lead to enhanced paper shrinkage. Out of the tested polysaccharides, alginate was found to be the most promising candidate for future packaging applications due to the fact that it gave strong and stiff model films, enhanced paper shrinkage, effectively lowered the air permeability of the paper, and formed a layer on the topside of the paper.

Acknowledgments Open access funding provided by Abo Akademi University (ABO). This work is a part of the project ExtBioNet, appointed by the Academy of Finland. Special thanks to technology student Richard Sundberg, Academic Lecturer Mari Nurmi at The Laboratory of Paper Coating and Converting, Åbo Akademi University, and PhD Vinay Kumar at The Laboratory of Paper Coating and Converting, Åbo Akademi University (currently with VTT).

Open Access This article is distributed under the terms of the Creative Commons Attribution 4.0 International License (http:// creativecommons.org/licenses/by/4.0/), which permits unrestricted use, distribution, and reproduction in any medium, provided you give appropriate credit to the original author(s) and the source, provide a link to the Creative Commons license, and indicate if changes were made.

\section{References}

Arvanitoyannis I, Biliaderis C (1999) Physical properties of polyol-plasticized edible blends made of methyl cellulose and soluble starch. Carbohydr Polym 38:47-58. https://doi. org/10.1016/S0144-8617(98)00087-3

BeMiller J, Whistler R (1996) Carbohydrates. In: Fennema O (ed) Food chemistry, 3rd edn. Marcel Dekker Inc., New York, pp 157-224

Chudzikowski R (1971) Guar gum and its applications. J Soc Cosmet Chem 22:43-60

Fornue E, Allan G, Quinones H, Gonzalez G, Saucedo J (2011) Fundamental aspects of adhesion between cellulosic surfaces in contact-a review. Papel 72:85-90

Gacesa P (1988) Alginates. Carbohydr Polym 8:161-182

Hubbe M (2006) Bonding between cellulosic fibers in the absence and presence of dry-strength agents - a review. Bioresources 1:281-318. https://doi.org/10.15376/biores. 1.2.281-318
Hubbe M, Nanko H, McNeal M (2009) Retention aid polymer interactions with cellulosic surfaces and suspensions: a review. Bioresources 4:850-906

Khakalo A, Filpponen I, Johansson L-S, Vishtal A, Lokanathan A, Rojas O, Laine J (2014) Using gelatin protein to facilitate paper thermoformability. React Funct Polym 85:175-184. https://doi.org/10.1016/j.reactfunctpolym. 2014.09.024

Khakalo A, Vishtal A, Retulainen E, Filpponen I, Rojas O (2017a) Mechanically-induced dimensional extensibility of fibers towards tough fiber networks. Cellulose 24:191-205. https://doi.org/10.1007/s10570-016-1102-z

Khakalo A, Kouko J, Filpponen I, Retulainen E, Rojas O (2017b) In-plane compression and biopolymer permeation enable super-stretchable fiber webs for thermoforming toward 3D structures. ACS Sustain Chem Eng 5:9114-9125. https://doi.org/10.1021/acssuschemeng. $7 \mathrm{~b} 02025$

Kouko J, Retulainen E (2018) The relationship between shrinkage and elongation of bleached softwood kraft pulp sheets. Nord Pulp Pap Res J 33:522-533. https://doi.org/ 10.1515/npprj-2018-3057

Lee K, Mooney D (2012) Alginate: properties and biomedical applications. Prog Polym Sci 37:106-126. https://doi.org/ 10.1016/j.progpolymsci.2011.06.003

Lindqvist H, Bialczak S, Willför S, Sundberg A (2014) Functionalization of paper surfaces by modified galactoglucomannans in paper. J For 3:6-12

Lindström T, Ankerfors M, Nordmark G (2016) On the nature of joint strength of paper-effect of dry strength agentsrevisiting the page equation. Nord Pulp Pap Res J 31:459-468. https://doi.org/10.3183/NPPRJ-2016-31-03p459-468

Mikkonen K, Heikkinen S, Soovre A, Peura M, Serimaa R, Talja R, Helén H, Hyvönen L, Tenkanen M (2009) Films from oat spelt arabinoxylan plasticized with glycerol and sorbitol. J Appl Polym Sci 114:457-466. https://doi.org/10. 1002/app.30513

Mudgil D, Barak S, Khatkar B (2014) Guar gum: processing, properties and food applications-a review. J Food Sci Technol 51:409-418. https://doi.org/10.1007/s13197-0110522-x

Page D (1969) A theory for the tensile strength of paper. Tappi 52:674-681

Page D, Tydeman P (1962) A new theory of the shrinkage, structure, and properties of paper. In: Bolam F (ed) Formation and structure of paper, vol 1. Tech. Sect. British Paper and Board Makers' Association, London, pp 397-425

Pelton R (2004) On the design of polymers for increased paper dry strength—a review. Appita J 57:181-190

Ravi Kumar M (2000) A review of chitin and chitosan applications. React Funct Polym 46:1-27. https://doi.org/10. 1016/S1381-5148(00)00038-9

Retulainen E, Ebeling K (1993) Fiber-fiber bonding and ways of characterizing bond strength. Appita J 46:282-288

Rhim J-W (2012) Physical-mechanical properties of agar/אcarrageenan blend film and derived clay nanocomposite film. J Food Sci 77:N66-N73. https://doi.org/10.1111/j. 1750-3841.2012.02988.x 
Rinaudo M (2006) Chitin and chitosan: properties and applications. Prog Polym Sci 31:603-632. https://doi.org/10. 1016/j.progpolymsci.2006.06.001

Seth R (2005) Understanding sheet extensibility. Pulp Pap Can 106:33-40

Shukla S, Mishra A, Arotiba O, Mamba B (2013) Chitosanbased nanomaterials: a state-of-the-art review. Int $\mathrm{J}$ Biol Macromol 59:46-58. https://doi.org/10.1016/j.ijbiomac. 2013.04.043

Strand A, Khakalo A, Kouko J, Oksanen A, Ketola A, Salminen K, Rojas O, Retulainen E, Sundberg A (2017) The effect of chemical additives on the strength, stiffness and elongation potential of paper. Nord Pulp Pap Res J 32:324-335. https://doi.org/10.3183/NPPRJ-2017-32-03-p324-335

Strand A, Kouko J, Oksanen A, Salminen K, Ketola A, Retulainen E, Sundberg A (2018) Boosting the elongation potential of paper by mechanical refining and additives. Proceedings, PaperCon 2018, Charlotte, NC, USA, Tappi Press

Svensson A, Lindström T, Ankerfors M, Östlund S (2013) 3Dshapeable thermoplastic paper materials. Nord Pulp Pap Res J 28:602-610. https://doi.org/10.3183/NPPRJ-201328-04-p602-610

Vishtal A, Retulainen E (2014a) Improving the extensibility, wet web and dry strength of paper by addition of agar. Nord Pulp Pap Res J 29:434-443. https://doi.org/10.3183/ NPPRJ-2014-29-03-p434-443

Vishtal A, Retulainen E (2014b) Boosting the extensibility potential of fibre networks: a review. Bioresources 9:7951-8001
Vishtal A, Hauptmann M, Zelm R, Majschak J-P, Retulainen E (2014) 3D forming of paperboard: the influence of paperboard properties on formability. Packag Technol Sci 27:677-691. https://doi.org/10.1002/pts.2056

Vishtal A, Khakalo A, Rojas O, Retulainen E (2015) Improving the extensibility of paper: sequential spray addition of gelatine and agar. Nord Pulp Pap Res J 30:452-460. https:// doi.org/10.3183/NPPRJ-2015-30-03-p452-460

Wahlström T (1999) Influence of shrinkage and stretch during drying on paper properties. Licentiate thesis, Royal Institute of Technology (KTH), Stockholm, Sweden

Yoo S, Krochta J (2011) Whey protein-polysaccharide blended edible film formation and barrier, tensile, thermal and transparency properties. J Sci Food Agric 91:2628-2636. https://doi.org/10.1002/jsfa.4502

Yu L, Dean K, Li L (2006) Polymer blends and composites from renewable resources. Prog Polym Sci 31:576-602. https:// doi.org/10.1016/j.progpolymsci.2006.03.002

Zeng X, Vishtal A, Retulainen E, Sivonen E, Shiyu F (2013) The elongation potential of paper-how should fibres be deformed to make paper extensible? Bioresources $8: 472-486$

Publisher's Note Springer Nature remains neutral with regard to jurisdictional claims in published maps and institutional affiliations. 